سينتيك آزاد شدن يُاسيم غيرتبادلى در خاكدانهاى با اندازه متفاوت در تعدادى از خاكهاى آهكى

\author{
سيده زهر اعطار شهركى، علير ضا حسين يور، حميدرضا متقيان" و شجاع قربانى' \\ (تاريخ دريافت:
}

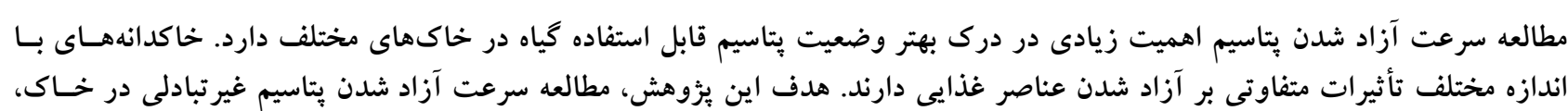

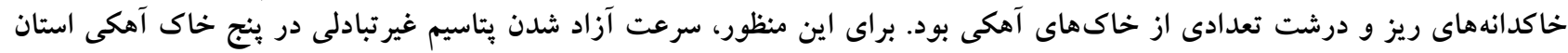

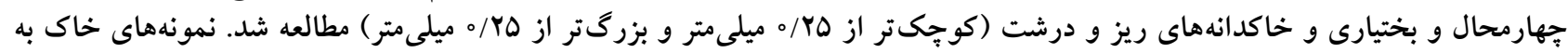

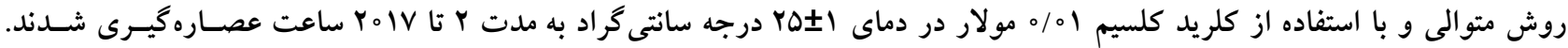

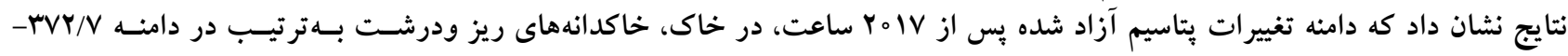
رئ IVT/D

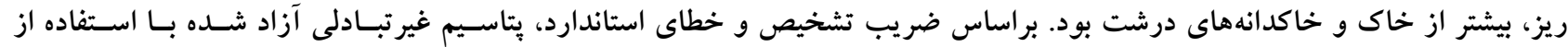

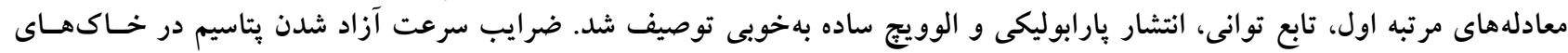

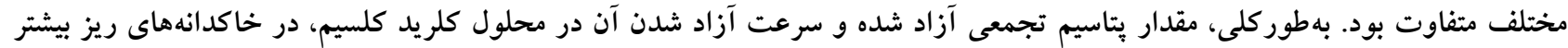

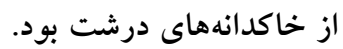

وازههاى كليدى: آزاد شدن بتاسيم غير تبادلى، خاكدانه، كلريد كلسيم، معادلههاى سينتيكى 
عصاره گيرهاى قوى مانند اسيد نيتريكى يـى مـولار و جوشـان

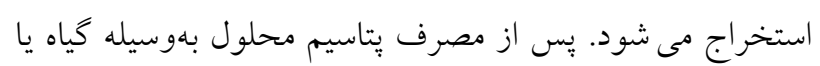

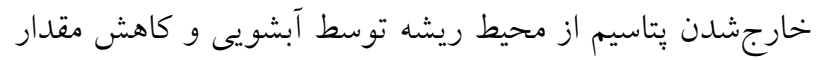

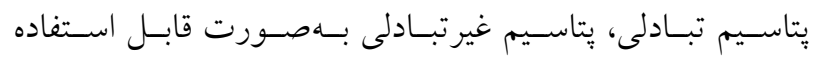

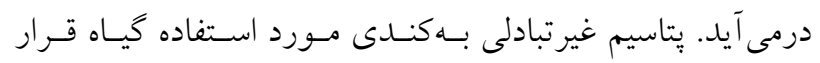

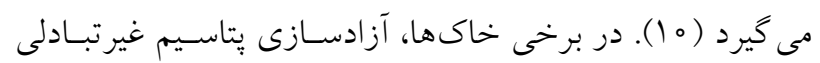

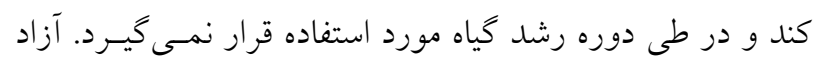

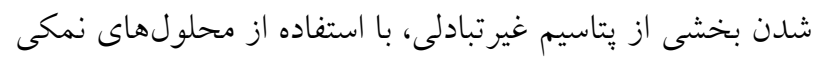

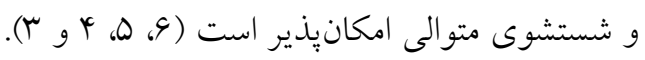

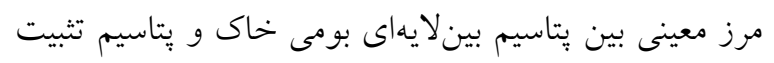

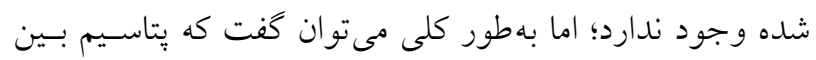

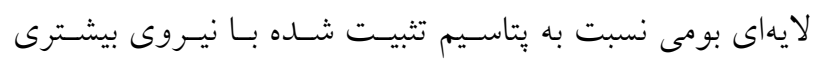

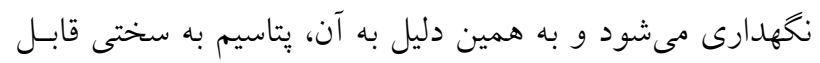

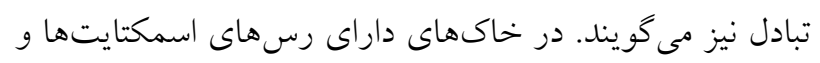

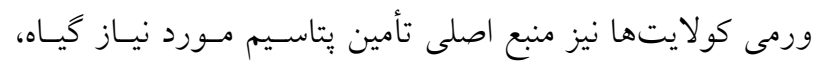

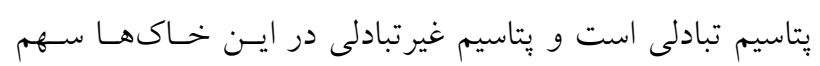

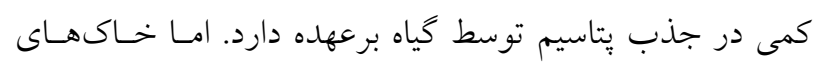

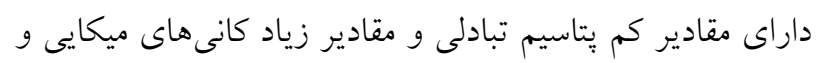

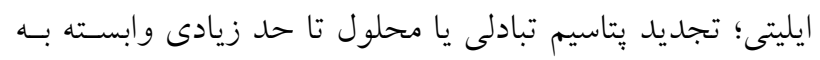

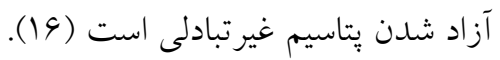
نقش بتاسيم غيرتبادلى خاك در تأمين بتاسيم مورد نياز كياه

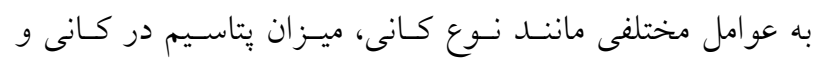

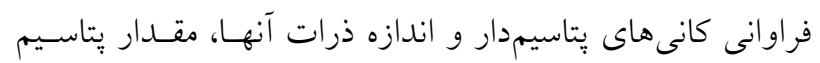

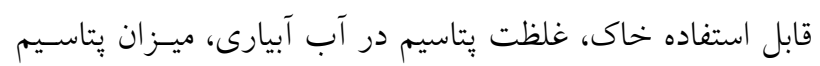

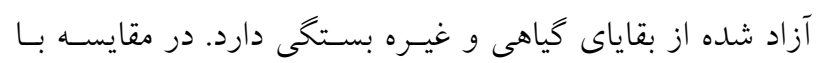
ذرات ريز خاك، ذرات درشت بهعلت هواديدكى كمتر، حساوى

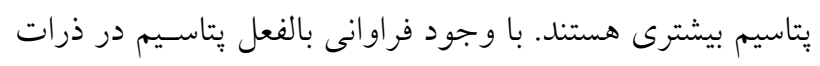

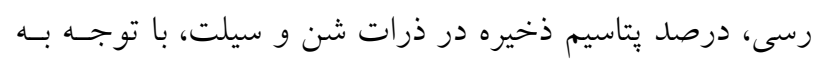

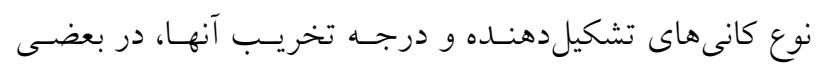

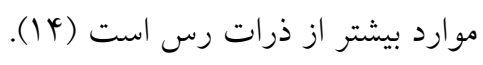

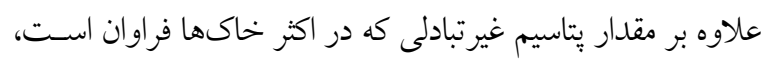
عامل مهم و عمده ديكر سرعت آزاد شدن و در دسـترس كيـاه قـرار

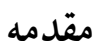

در جهان امروز، يكى از مشكلات اساسى بشـر تـأمين نيازهـاى

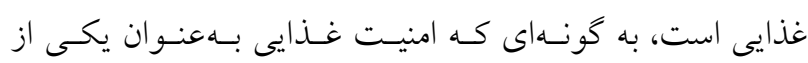

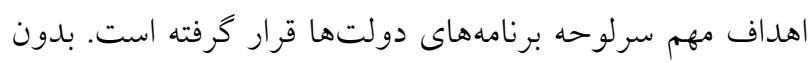

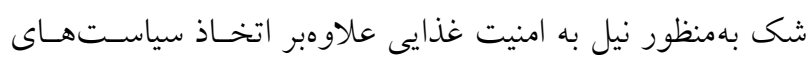

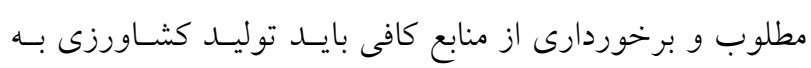

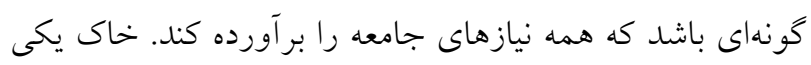

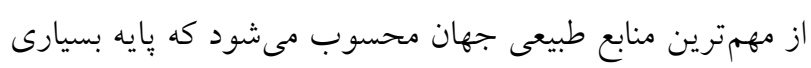

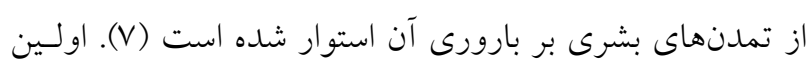

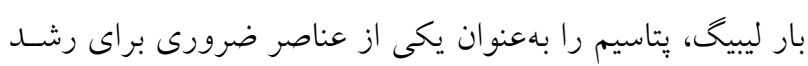

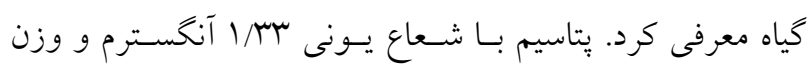

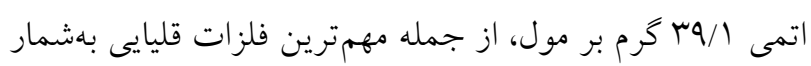

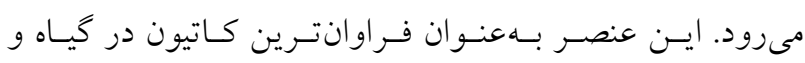

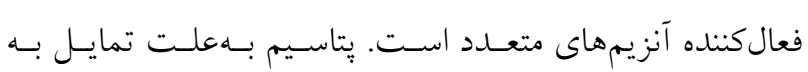
واكنش و ميل تركيبى بالا با ساير عناصر، به شكل عنصرى يافت

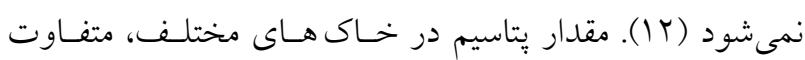

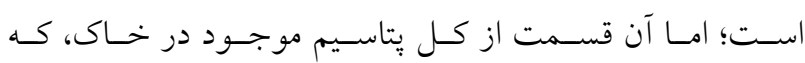

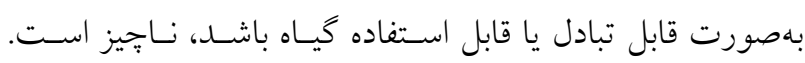

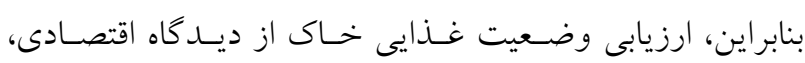
محيطى و تغذيه مهم است.

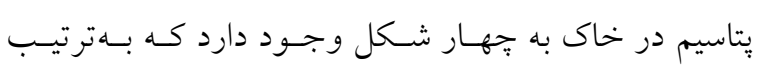

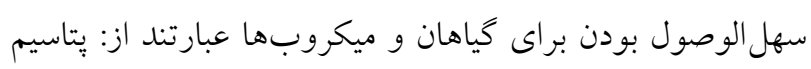

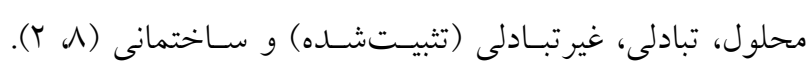

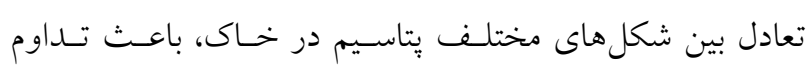

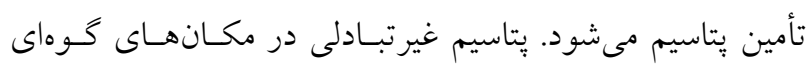

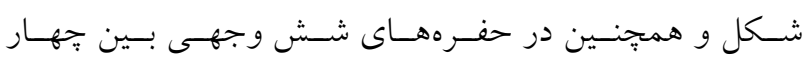

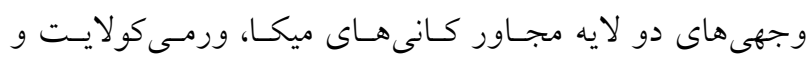

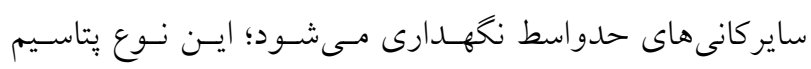

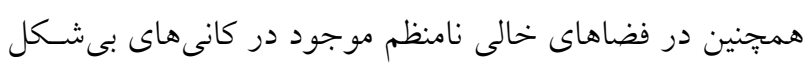

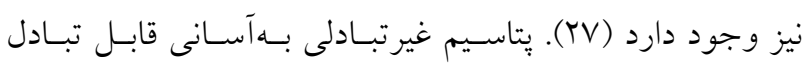

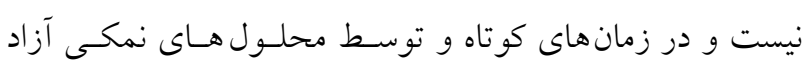

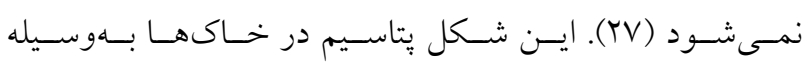


يتاسيم غيرتبادلى ينج نمونه خاك براسـاس دارا بـودن بيشـترين

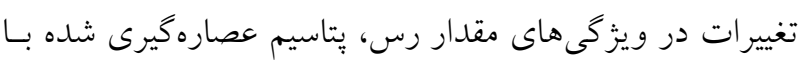

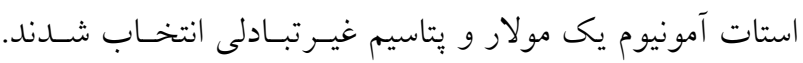

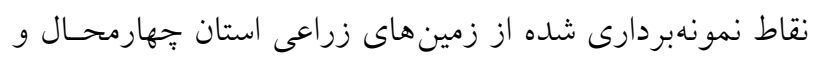

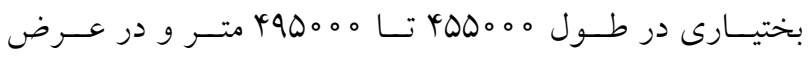
每 خصوصيات فيزيكى و شيميايى نمونهها شامل توزيع انـازها

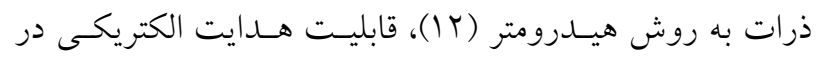

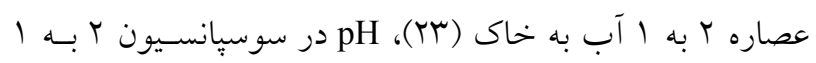

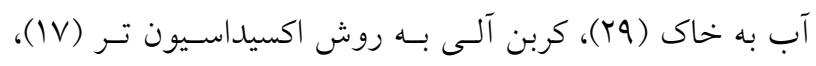

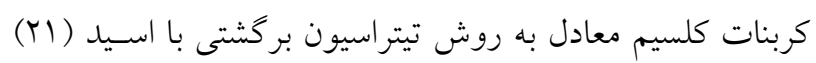

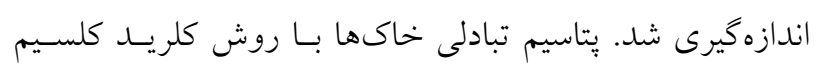

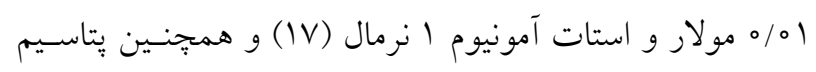

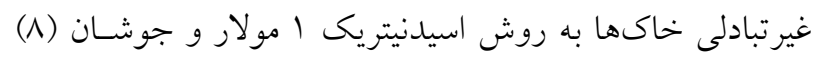

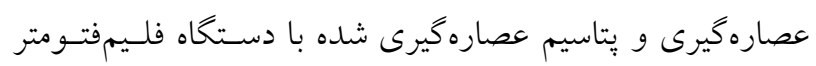

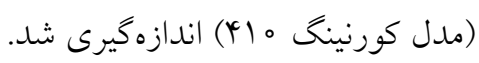

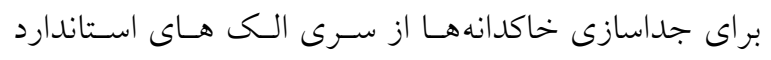

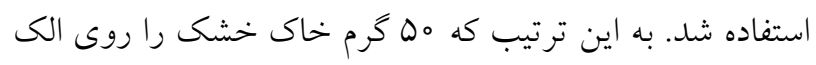

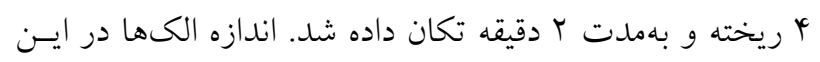

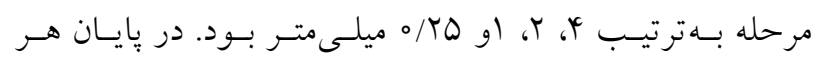

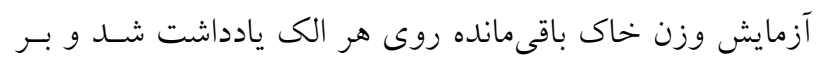

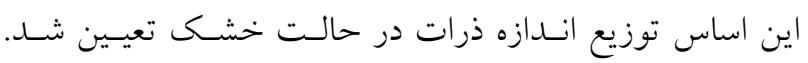

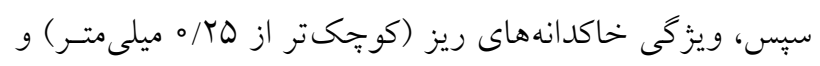

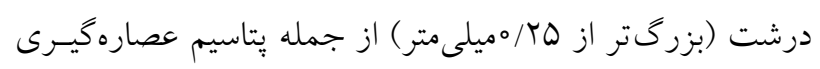

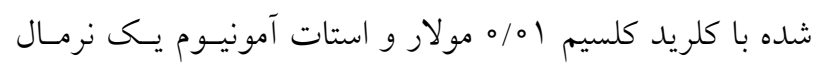

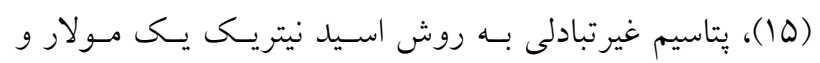

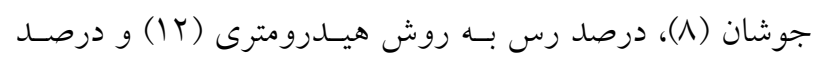

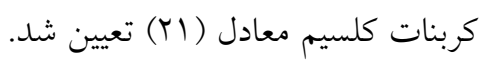

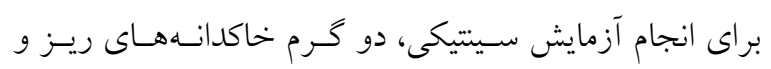

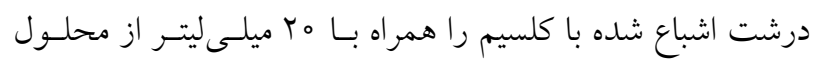

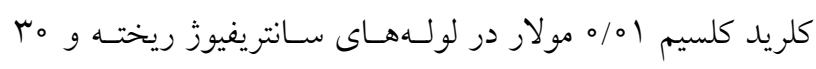
دقيقه نمونه ها بلوسيله استفاده تكاندهنده برقى تكان داده شــندلد.
كُفتن اين جزء از بِتاسيم در طول دوره رشـــ كيـاه اسـت. اطـلاع از درصد سهم هريك از اجزاى تشكيل دهنده خـاك در تـأمين بتاستيم

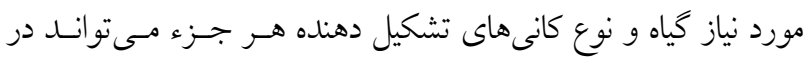

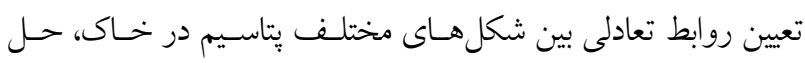

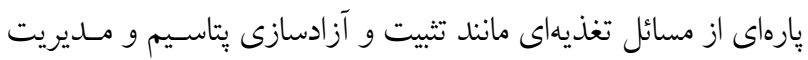

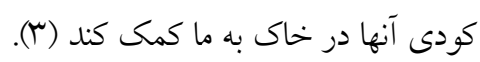
خاكدانها، ذرات ثانويهاى هستند كه در اثر همـاورى ذرات

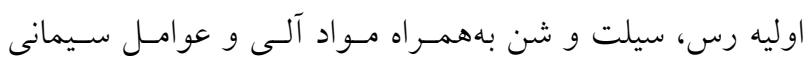

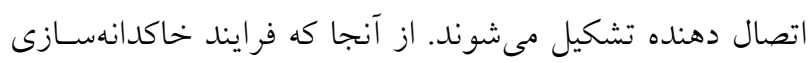

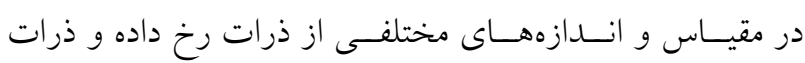
بزرگتر از هماورى ذرات كوجى دتر تشكيل مىشوند؛ بنسابر اين،

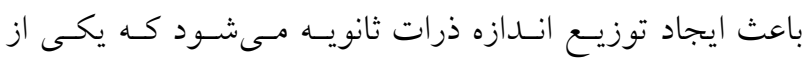

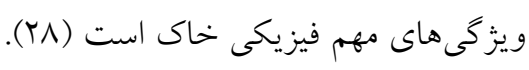

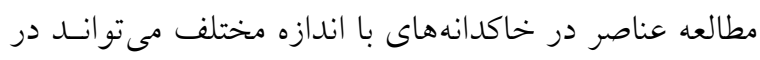

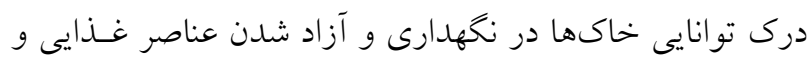

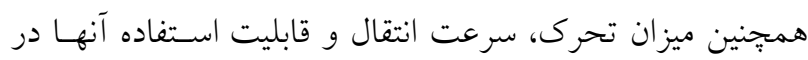

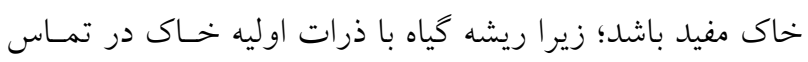

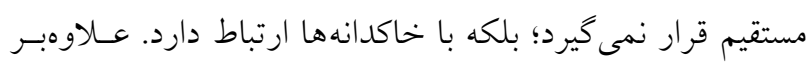

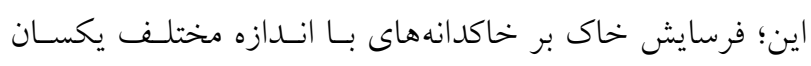

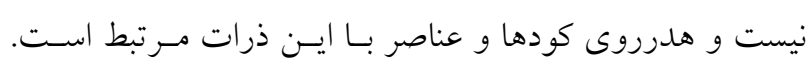

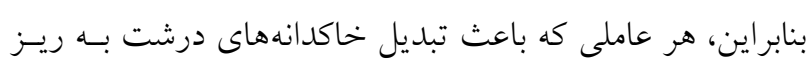

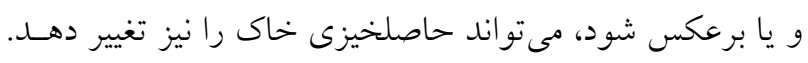

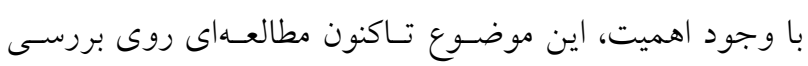

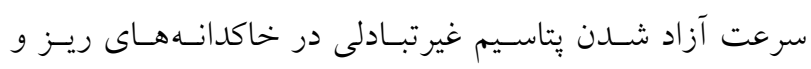

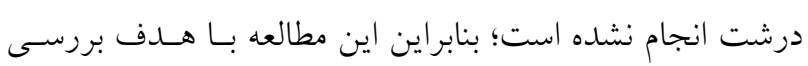

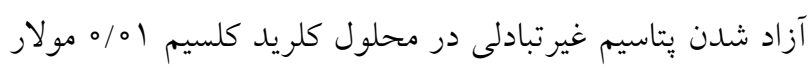

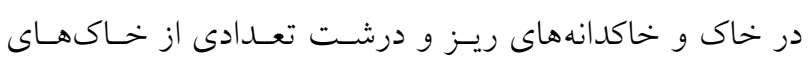

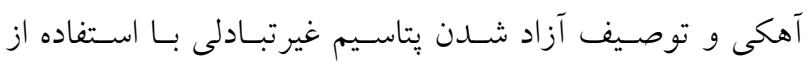
معادلههاى سينتيكى انجام شد.

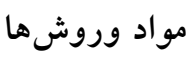

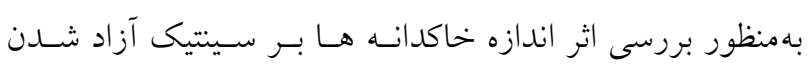


نشريه علوم آب و خاك (علوم و فنون كثاورزى و منابع طبيع) / سال بيست و دو / شماره يك/ بهار IraV

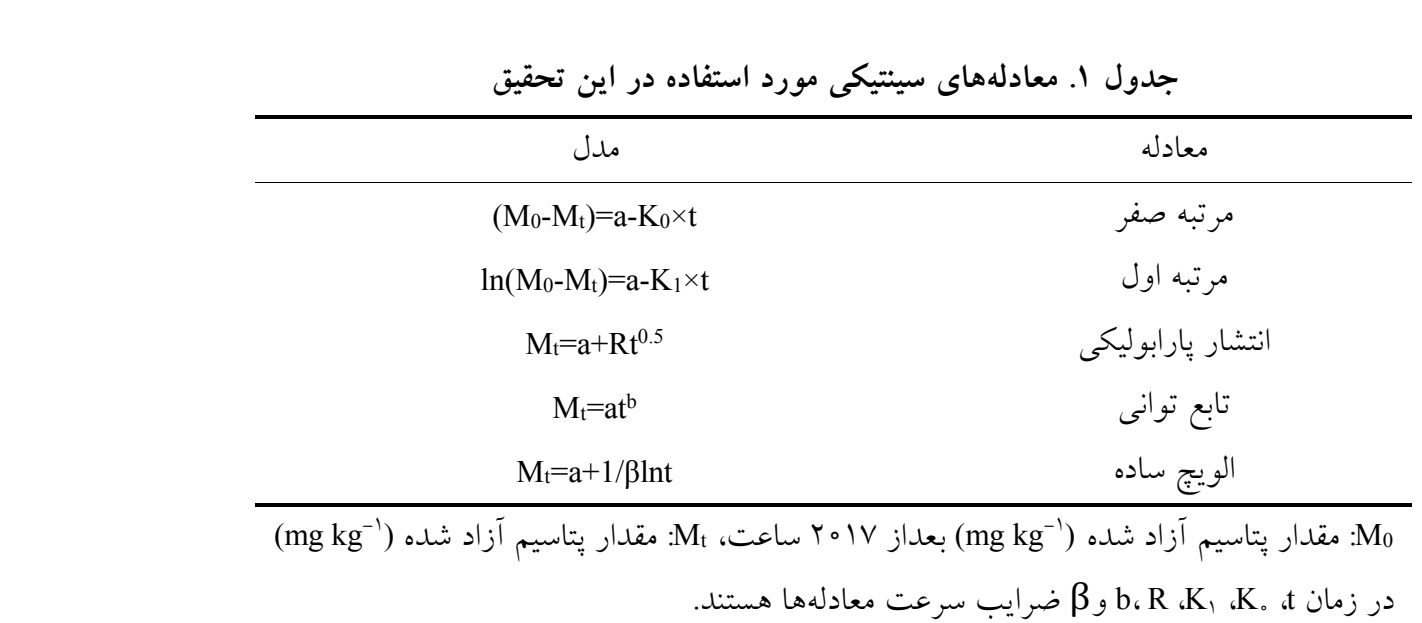

$\mathrm{SE}=\left[\sum\left(\mathrm{K}-\mathrm{K}^{*}\right)^{\Upsilon} / \mathrm{n}-\mathrm{r}\right]^{0 / \Delta}$

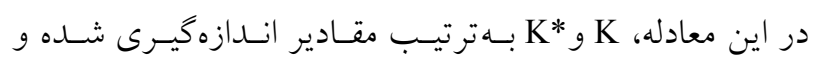

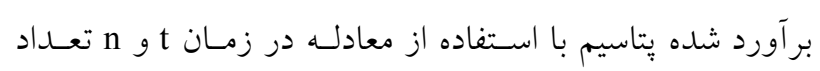
مشاهدها هستند.

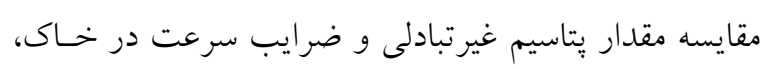

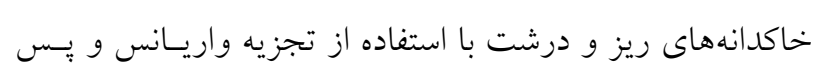

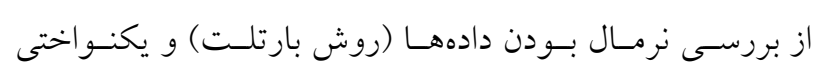

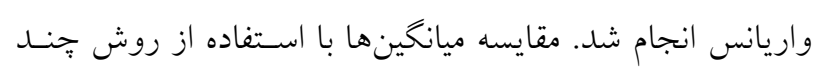
دامنه دانكن در سطح احتمال ه درصد بـا اسـتفاده از نـرمافـزار Statistica

\section{نتايج و بحث}

برخى ويزگى هاى فيزيكى و شيميايى خاكهاى مورد مطالعه در

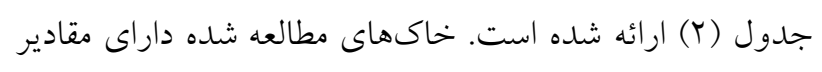

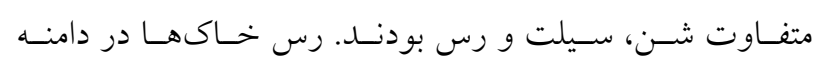
IV-OF/Y

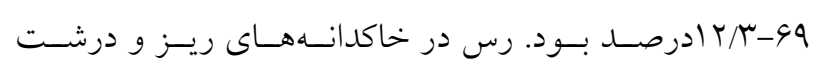

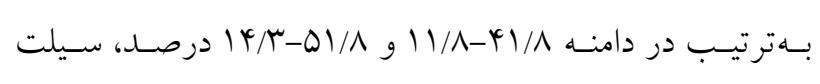

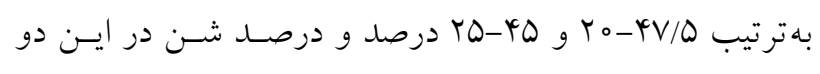

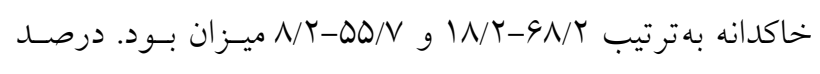

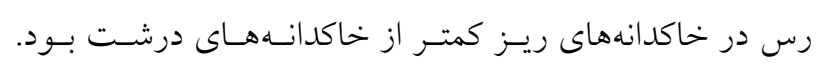

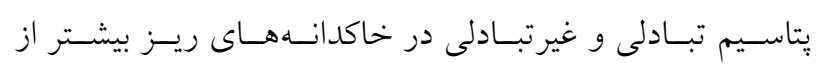

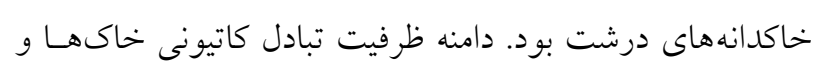

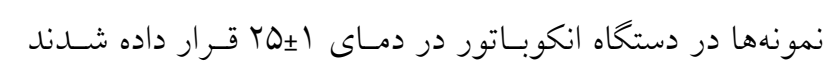

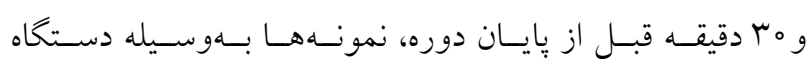

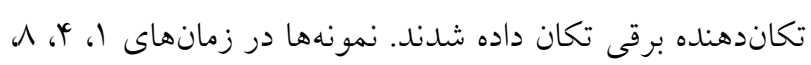

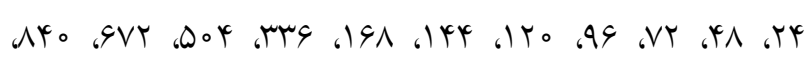

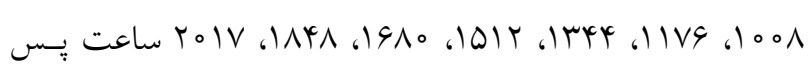
از اضافهكردن كلريد كلسيم عصارهگيرى شدند. براى اين منظور

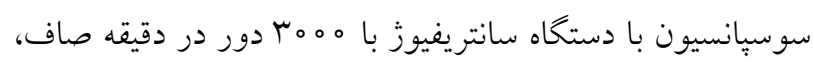

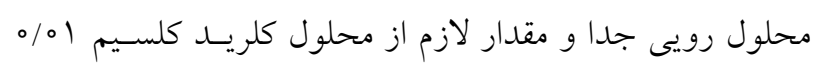

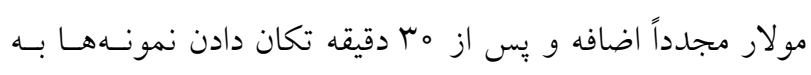

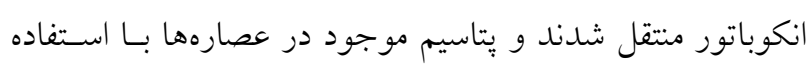

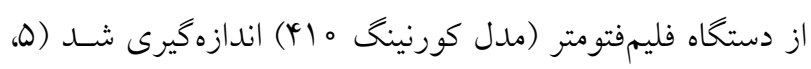

(r

قِ إز جمع آورى دادهها، معادلههاى مرتبه صفر، مرتبه اول،

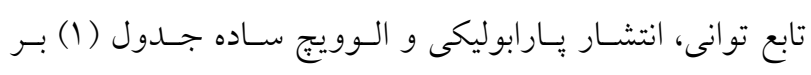

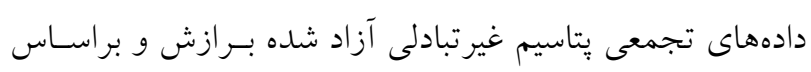

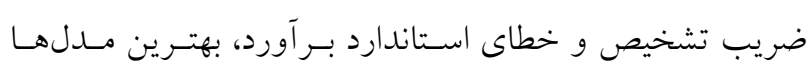

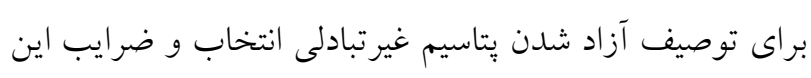
معادلههاى تعيين شدند (Y). با مقايسه ضريب تشخيص (RE) و خطاى استاندارد بـر آورد

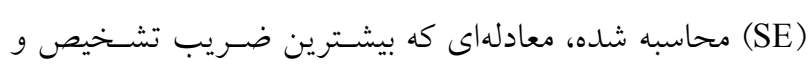

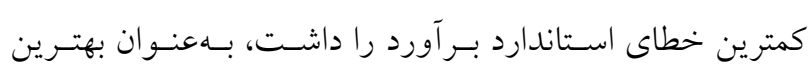

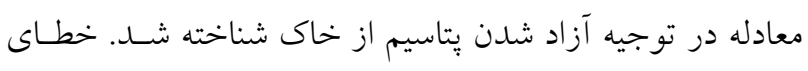
استاندارد از رابطه زير تعيين شد: 
جدول r. ويزگ گهاى فيزيكى و شيميايى خاكهاى مورد مطالعه

\begin{tabular}{|c|c|c|c|c|c|c|c|c|c|c|}
\hline سيلت & رس & كربنات كلسيم & ماده آلى & \multirow[t]{2}{*}{$\begin{array}{c}\mathrm{CEC} \\
\left(\operatorname{cmol}(+) \mathrm{kg}^{-1}\right)\end{array}$} & غير تبادلى & تبادلى & \multirow[t]{2}{*}{ 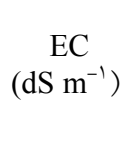 } & \multirow[t]{2}{*}{$\mathrm{pH}$} & & \multirow[t]{2}{*}{ خاى } \\
\hline \multicolumn{4}{|c|}{$(\%)$} & & \multicolumn{2}{|c|}{$\left(\mathrm{mg} \mathrm{kg}^{-1}\right)$} & & & & \\
\hline$\psi_{0}$ & rr & $r Q / q$ & $0 / 99$ & IN/V & TI9T & rVA & ת & $\Lambda / 1$ & خاك & 1 \\
\hline KY & me & YN/T & 1/or & $19 / 4$ & TMMY & 0.9 & $0 /$ YA & $\Lambda / \circ$ & خاكدانه ريز & \\
\hline id & py & $r \mu / \varphi$ & $\circ / 19$ & $r \circ / \Lambda$ & 1991 & $Y \Delta \Delta$ & O M & $\Lambda / 1$ & خاكدانه درشت & \\
\hline ry & $\Delta r$ & $r q / 9$ & $\circ / \Delta Q$ & $19 / \mu$ & $19 V T$ & per & $0 / M$ & $\Lambda / \Gamma$ & خاى & r \\
\hline ro & et & $\mathrm{rV} / \mathrm{V}$ & $0 / 9 Y$ & $\mid \Lambda / r$ & rTar & ror & Tr & $\Lambda / 1$ & خاكدانه ريز & \\
\hline ro & Or & $M Y / Y$ & $\circ \mu k$ & $19 / 9$ & 1119 & Trt & $\circ / T \wedge$ & $\Lambda / \circ$ & خاكدانه درشت & \\
\hline kt & 41 & $M Y / D$ & $0 / 94$ & $1 \mathrm{~V} / 0$ & $1 \wedge \vee \Delta$ & org & O/Y & $\Lambda / r$ & خاى & r \\
\hline kV & rt & $4 \circ / 0$ & $\circ / N Q$ & IV/V & THO & Drq & $0 / 4 q$ & $\Lambda / r$ & خاكدانه ريز & \\
\hline ro & \&V & $r V / T$ & $\circ / \Delta \Delta$ & $1 V / 0$ & IAVQ & $01 \%$ & $0 / \mu Y$ & $\Lambda / T$ & خاكدانه درشت & \\
\hline 14 & IV & $T Y / Y$ & $\circ / \Delta \Delta$ & $11 / 9$ & IEYA & ror & $O / M Y$ & $\Lambda / \circ$ & خاى & y \\
\hline ro & Ir & $r Q / \circ$ & . & $10 / 1$ & MNG & $4 q 0$ & $0 / T \wedge$ & $\Lambda / \circ$ & خاكدانه ريز & \\
\hline 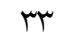 & 14 & $T Y / V$ & ०/AY & $I T / T$ & $19 \pi$ & rVA & $0 / 49$ & $\Lambda / \circ$ & خاكدانه درشت & \\
\hline 19 & 11 & $T Y / \Lambda$ & $\circ / 19$ & $9 / \pi$ & 1990 & raq & $0 / M_{1}$ & $\Lambda / \circ$ & خاى & 0 \\
\hline Tr & 14 & $T G / T$ &.$/ 99$ & $9 / r$ & $19 V T$ & rar & $0 / 40$ & $\mathrm{~V} / \mathrm{\Lambda}$ & خاكدانه ريز & \\
\hline TQ & 19 & TH/D & O/AY & $9 / \mathrm{V}$ & $|A Y|$ & rvq & OMT & $\Lambda / \circ$ & خاكدانه درشت & \\
\hline
\end{tabular}

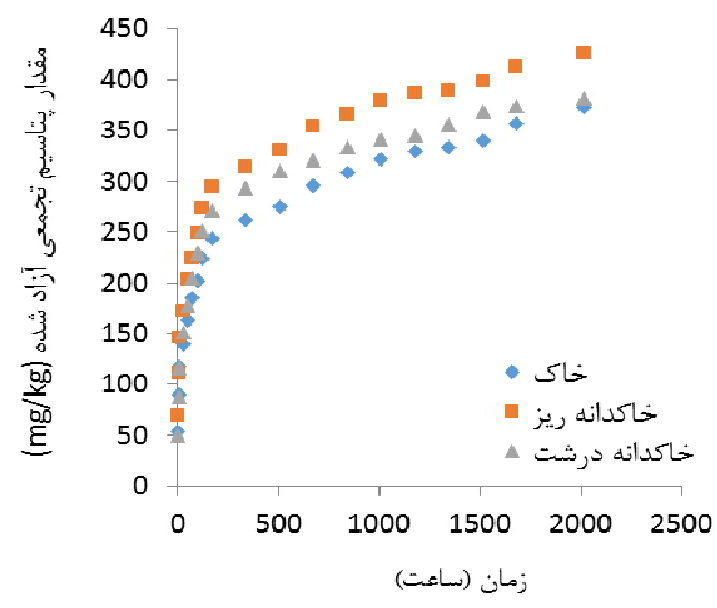

شكل ا. نمودار مقدار تجمعى پتاسيم آزاد شده در كلريد كلسيم در خاك، خاكدانهاى ريز و درشت شماره 1

سرعت آزاد شدن بتاسيم غيرتبادلى از اين خـاكهـا در مراحـل

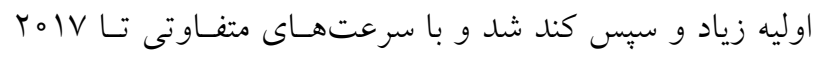

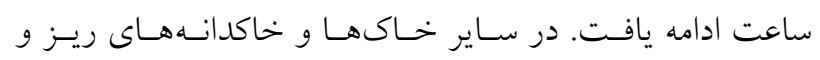

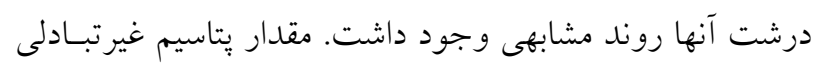

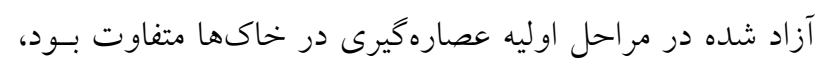

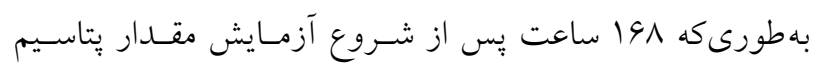

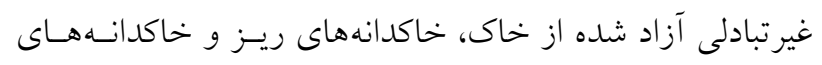

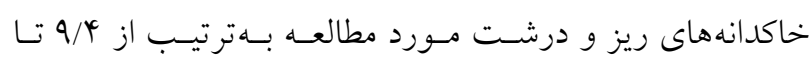

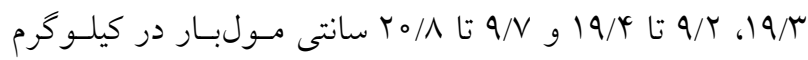
خاك است. دامنه pH تغييرات جُندانى نداشت و همه خـاكهـا

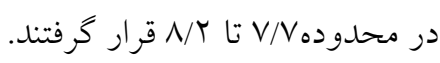

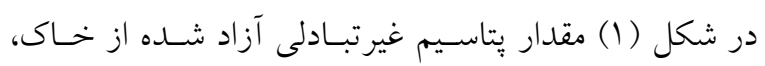

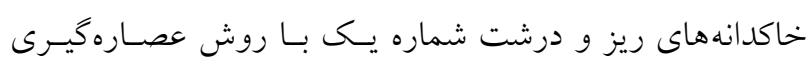

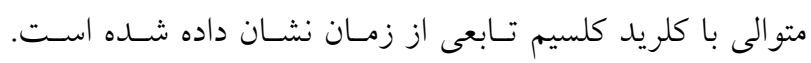




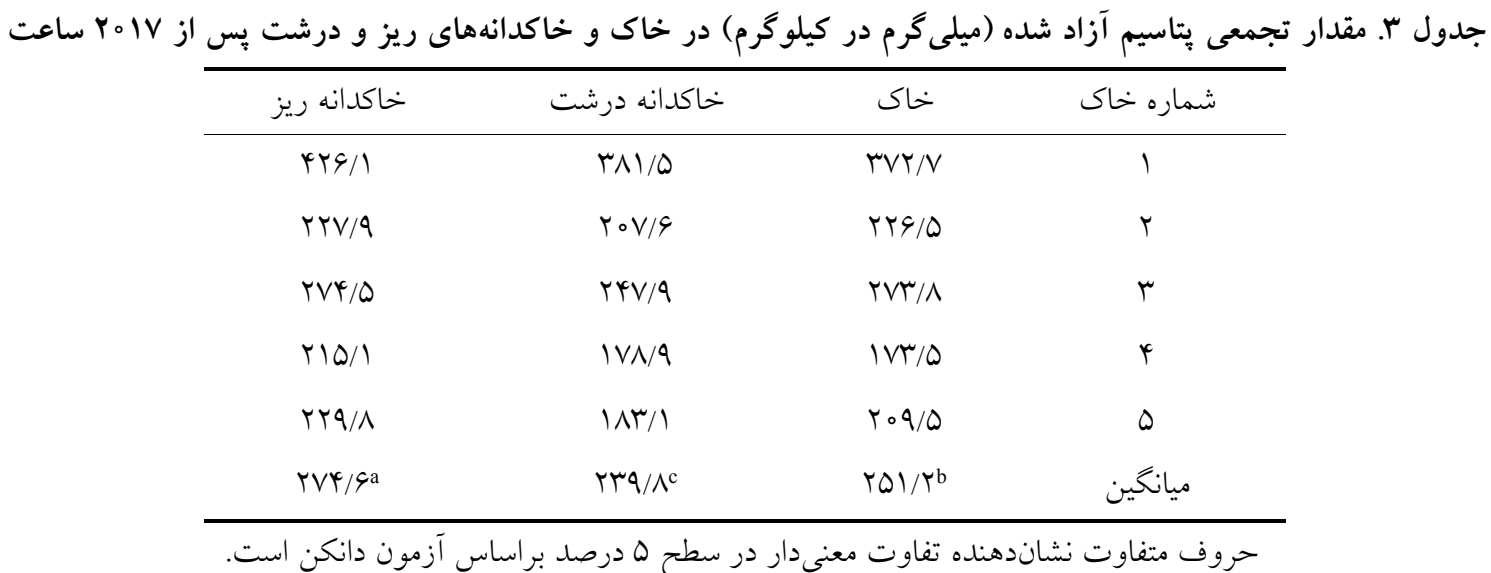

يتاسيم بين لايهاى بو مى كانىها، نسبت به يتاسيم تثبيت شـده بـا نيروى بيشترى نخهارى مىشود. تفاوت درصـد سـيلت و رس

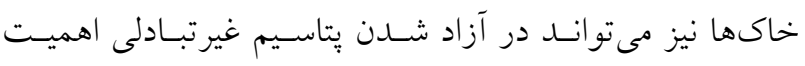

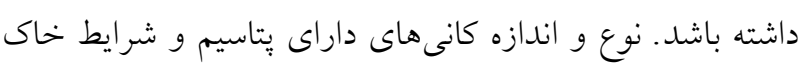

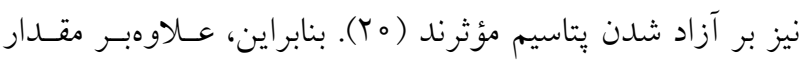

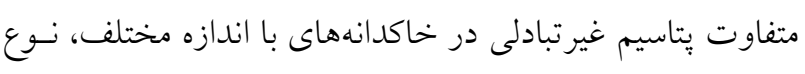
و مقدار كانى هاى رسى در بخش رس و سيلت (نه درصد آنهـا) نيز مى توانند از عوامل مؤثر بر مقدار يتاسيم غيرتبادلى آزاد شــده در خاكها باشد (ب و ؟ا). مقايسه مقادير يتاسـيم غيرتبـادلى آزاد

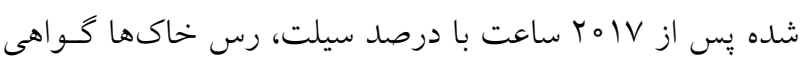
بر اين ادعاست. در اين تحقيق مقدار پِاسيم غيرتبادلى آزاد شده

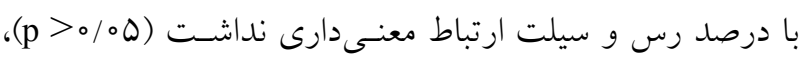
بنابراين، ممكن است در خاكى عليرغم داشتن درصد رس و يـا سيلت يكسان بهدليل تفاوت نوع و مقدار كانىهاى رسى، مقدار بتاسيم غيرتبادلى آزاد شده متفاوت باشد. همه اين عوامل منجـر

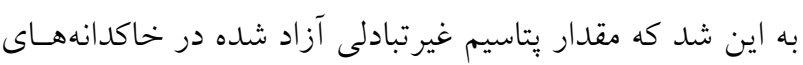
ريز بيشتر از خاكدانههاى درشت باشد.

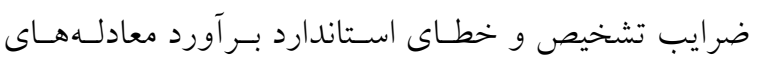
سينتيكى مورد استفاده در توصسيف سـرعت آزاد شـدن بِّاسـيم غيرتبادلى در خاك، خاكدانههاى ريـز و درشـت در جـدول (4) آورده شده است. با توجه به نتايج، بـهدليـل كـم بــودن ضـريب تشخيص، معادله مرتبه صفر قادر به توصيف آزاد شـدن بِّاسـيم غيرتبادلى در خاك، خاكدانههـاى ريـز و درشـت نبـود و سـاير
درشـت بـهترتيـب در دامنـه

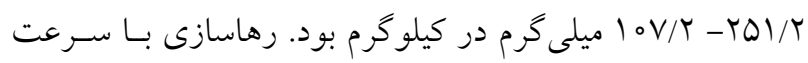
بالا در مراحل اوليه را مىتوان بـهـ آزاد شــدن بتاسـيم از منـاطق

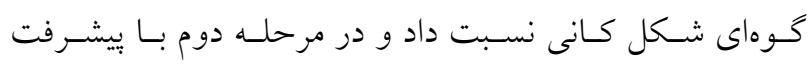
رهاسازى و بالا رفتن انرزى جذب يتاسيم در بـين لايسههـا و از طرفى افزايش فاصله يتاسيم از لبههاى كـانى و افززايش فاصسله يخشيدكى، سرعت رهاسازى كاهش مى يابد (س، لا، ه). بيشترين مقدار يتاسيم غيرتبادلى از خاك شماره ا و كمترين مقدار آن از

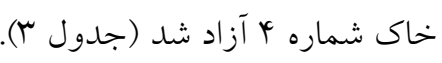
يتاسيم غيرتبادلى آزاد شده يس از YolV ساعت درخاكهـا،

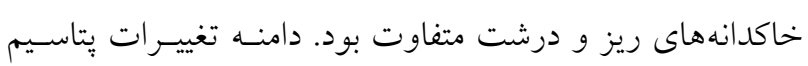

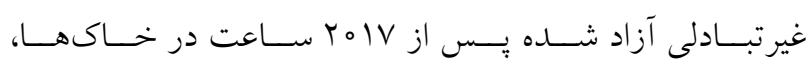

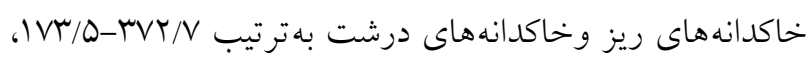

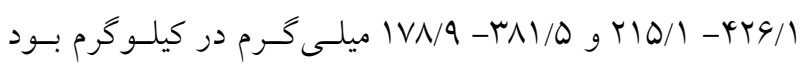
(جدول ץ). تفاوت در مقدار يتاسيم غيرتبادلى آزاد شده در ايسن خاكها را مىتوان به مقدار يتاسيم غيرتبـادلى آنهـا جــدول (Y)

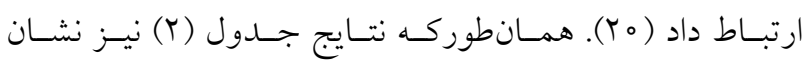

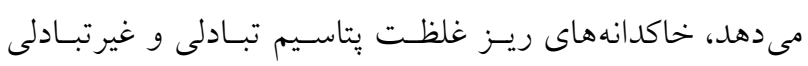
بيشترى نسبت به كل خـاك و خاكدانسهــاى درشـت داشـتند و همجنين ارتبـاط مثبـت و معنسى دارى (r=0/AY p >0/00 بـين يتاسيم غيرتبادلى و يتاسيم آزاد شده در محلـول كلريـــ كلسـيم 10 / مولار بهدست آمد. يتاسيم غيرتبـادلى شـامل پِّاسـيم بـين

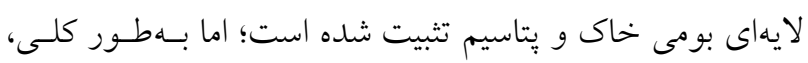


جدول †. ضريب تشخيص (RE) و خطاى استاندارد بر آورد (SE) معادله (Rاى مختلف مورد استفاده در توصيف يتاسيم آزاد شده در خاكهاى مورد مطالعه

\begin{tabular}{|c|c|c|c|c|c|c|c|c|c|c|c|}
\hline \multicolumn{2}{|c|}{ تابع توانى } & \multicolumn{2}{|c|}{ الوويج ساده } & \multicolumn{2}{|c|}{ انتشار پيار ابوليكى } & \multicolumn{2}{|c|}{ مرتبه اول } & \multicolumn{2}{|c|}{ مرتبه صفر } & & \multirow{2}{*}{ 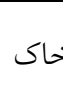 } \\
\hline SE & $\mathrm{R}^{r}$ & SE & $\mathrm{R}^{r}$ & SE & $\mathrm{R}^{r}$ & SE & $\mathrm{R}^{r}$ & SE & $\mathrm{R}^{r}$ & & \\
\hline $1 r$ & $0 / 91$ & $14 / V$ & $\circ / 9 \mathrm{~V}$ & $r V / q$ & $0 / 9 Y$ & 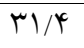 &.$/ 94$ & $49 / \mu$ & o/VG & خاك & 1 \\
\hline 19 & $0 / 91$ & $1 \mu / \mathrm{V}$ & $0 / 9$ & $M Y / Q$ & $\circ / 9 V$ & rV $/ \mathrm{V}$ & $\circ / 90$ & $\Delta Q / \Lambda$ & $\circ / Y^{C}$ & خاكدانه ريز & \\
\hline IV & $0 / 91$ & $11 / 1$ & $\circ / 9 \circ$ & $m / / 9$ & $\circ / 9 V$ & $r \Delta / c^{c}$ &.$/ 90$ & $01 / 9$ & $\circ / V^{C}$ & خاكدانه درشت & \\
\hline $\mathrm{V} / \mathrm{l}$ & $0 / 91$ & $10 / V$ &.$/ 99$ & $19 / \mathrm{V}$ & $0 / 91$ & $1 N / \Lambda$ & $0 / 99$ & $r V / D$ & $\circ / \mathrm{V} \Lambda$ & خاى & r \\
\hline$V / T$ & $0 / 99$ & $11 / 0$ & . & $19 / 4$ & $0 / 91$ & $19 / \pi$ &.$/ 90$ & $r \Lambda / r$ & $\circ / \mathrm{VV}$ & خاكدانه ريز & \\
\hline 11 & $0 / 91$ & $Q / \omega$ & $0 / 9$ & $\mathrm{IV} / \mathrm{V}$ &.$/ 90$ & $r \circ / \Lambda$ &.$/ 90$ & $r \Lambda / 4$ & $\circ / N$ & خاكدانه درشت & \\
\hline $\mid r / r$ & $0 / 99$ & $9 / \mu$ & $0 / 91$ & $Y Y / l$ & $0 / 91$ & YYN &.$/ 94$ & $r \Delta / r$ & $\circ / V Q$ & خاك & $r$ \\
\hline $1 / 9$ & $\circ / 94$ & $M / V$ &.$/ 9 T$ & $1 N / 1$ & $\circ / 91$ & $r \circ / q$ &.$/ 90$ & $r+/$ & $\circ / \mathrm{VV}$ & خاكدانه ريز & \\
\hline$T Q / \varphi$ & $0 / 91$ & $r \mid / 9$ & $0 / 91$ & $r G / T$ & $\circ / 9 V$ & $r M / 4$ &.$/ 90$ & $m 1 / 4$ & $\circ / V Q$ & خاكدانه درشت & \\
\hline$\varphi / 4$ & $0 / 99$ & $11 / 9$ &.$/ 94$ & $10 / 4$ & $\circ / 90$ & $\mid r / 4$ &.$/ 94$ & $19 / 0$ & O/AY & خاى & r \\
\hline $9 / 1$ & $0 / 99$ & $9 / 9$ & $\circ / 94$ & $10 / 1$ & $0 / 91$ & $I V / 4$ &.$/ 90$ & $r 9 / T$ & $\circ / \mathrm{VV}$ & خاكدانه ريز & \\
\hline$\Delta / V$ & $\circ / 9 V$ & $V / I$ & . & $\mid r / 1$ & $0 / 91$ & $14 / 9$ & $0 / 99$ & $r Y / 1$ & $\circ / \mathrm{V} \Lambda$ & خاكدانه درشت & \\
\hline 0 & $0 / 99$ & $1 / 9$ & $0 / 99$ & $1 r / \Lambda$ & $0 / 94$ & $19 / 9$ & $0 / 99$ & $r M / \Lambda$ & $\circ / \sqrt{ } 9$ & خاى & 0 \\
\hline $9 / 4$ & $\circ / 9 V$ & $\Lambda / r$ & $0 / 91$ & $19 / 4$ & $\circ / 91$ & $19 / 0$ &.$/ 90$ & $r V / l$ & $\circ / V 9$ & خاكدانه ريز & \\
\hline$\Delta / V$ & $\circ / 9 V$ & $V / T$ & $\circ / 94$ & $I T / T$ & $0 / 91$ & 10 & $\circ / 90$ & $r \circ / \Lambda$ & $\circ / \sqrt{ } 9$ & خاكدانه درشت & \\
\hline
\end{tabular}

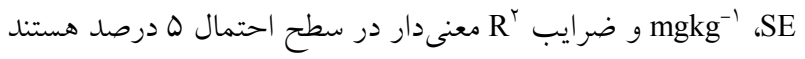

برروى سرعت آزاد شدن يتاسيم غيرتبادلى از خاى و اجزاى آن در تعدادى از خاى هاى استان كلستان انجام دادنــــ آنهـا نشـان دادند كه مقدار بِتاسيم غيرتبادلى آزاد شده در زمانهاى مختلـف

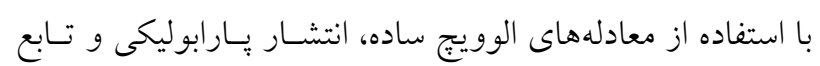
توانى به خــوبى توصسيف شــده اسـت. ويكـاس و شـارما ( (Y) مطالعات خود را بر روى سينتيكهاى آزاد شدن يتاسيم بر روى برى خاكهاى آبرفتى شمال غرب هنـــ انجــام دادنـــ. سـينتيك آزاد شدن يتاسيم با استفاده از معادلههاى رياضى ارزيابى شد. معادله

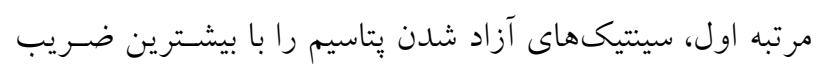
تشخيص و كمترين خطاى استاندارد، به بهترين شكل توصسيف

ضـرايب سـرعت معادلـهـــاى سـيتيكى مــورد اسـتفاده در توصيف يتاسيم غيرتبادلى آزاد شده در خاك، خاكدانههـاى ريـز و درشت در جدول (ه) نشـان داده شـده اسـت. ضـريب b در معادله تابع توانى نشان دهنده سرعت آزاد شـدن يتاسـيم اسـت.

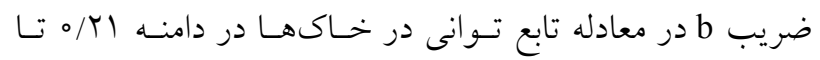

معادلهها قادر به توصيف آزاد شدن يتاسيم غيرتبادلى بودند. در مطالعـات متعـددى بـهـ توانـايى مــلـهـاى مختلـفـ در

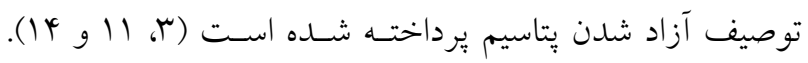

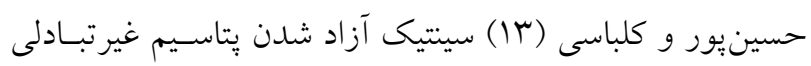

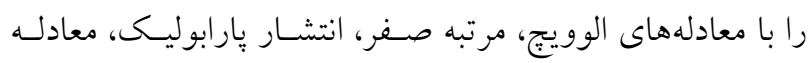

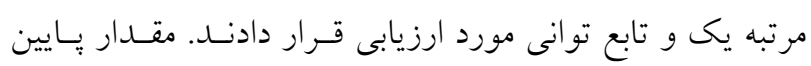
ضريب تشخيص و بالا بودن خطا نشان داد كه معادله الـوويجج و درجه صفر، نمىتواند آزاد شدن يتاسـيم غيرتبـادلى را توصسيف كنند. در مقابل معادله انتشار يارابوليكى، معادله مرتبه اول و تابع

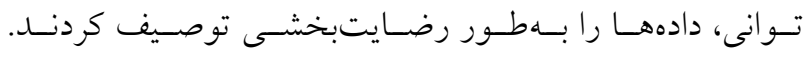

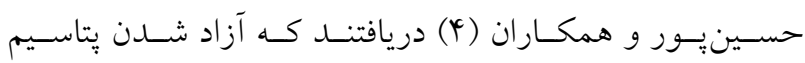
غيرتبادلى با استفاده از محلول كلريــ كلسـيم و اسـيد سـيتريك

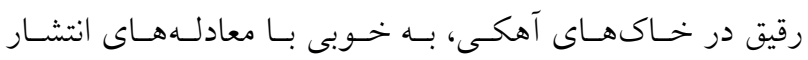
يارابوليكى، تابع توانى والوويج ساده شده در هر دو بخش ب تـا

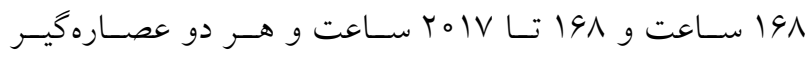
توصسيف شـد. فرشـادى اد و همكـاران (9) مطالعـات خــود را 
جدول ه. ضرايب سرعت معادله هاى سينتيكى مورد استفاده در توصيف يّاسيم غيرتبادلى آزاد شده

\begin{tabular}{|c|c|c|c|c|c|c|c|c|c|}
\hline \multicolumn{2}{|c|}{ تابع توانى } & \multicolumn{2}{|c|}{ الوويج ساده } & \multicolumn{2}{|c|}{ انتشاريارابوليكى } & \multicolumn{2}{|c|}{ مرتبه اول } & \multicolumn{2}{|l|}{ خاك } \\
\hline $\mathrm{b}$ & $\mathrm{a}$ & $1 / \beta$ & $\mathrm{a}$ & $\mathrm{R}$ & $\mathrm{a}$ & $\mathrm{K} 1 \times 10^{-*}$ & $\mathrm{a}$ & & \\
\hline$\left(\mathrm{mg} \mathrm{kg}^{-1}\right) \mathrm{h}^{-1}$ & $\left(\mathrm{mg} \mathrm{kg}^{-1}\right)$ & $\left(\mathrm{mg} \mathrm{kg}^{-1}\right) \mathrm{h}^{-1}$ & $\left(\mathrm{mg} \mathrm{kg}^{-1}\right)$ & $\left(\mathrm{mg} \mathrm{kg}^{-1}\right) \mathrm{h}^{-1 / r}$ & $\left(\mathrm{mg} \mathrm{kg}^{-1}\right)$ & $\left(\mathrm{mg} \mathrm{kg}^{-1}\right)^{-1}$ & $\left(\mathrm{mg} \mathrm{kg}^{-1}\right) \mathrm{h}$ & & \\
\hline D & $r / r$ & $x+/ 1$ & $T / / 0$ & $9 / 10$ & $111 / 19$ & 19 & $0 / 4 \pi$ & خاى & 1 \\
\hline O/KT & $\varphi / 4$ & $\Psi \wedge / \Lambda$ & rVN & $9 / 9$ & $1 \times 9 / 4$ & IV & $0 / 01$ & خاكدانه ريز & \\
\hline$O / M Y$ & $4 / 1$ & $k 4 / q$ & rt & $9 / 4$ & $1 Y \circ / 9$ & 19 & $\Delta / 4 \Delta$ & خاكدانه درشت & \\
\hline $0 / M Y$ & $r / 9$ & re/9 & $9 / 4^{4}$ & r/A & 90 & 14 & $4 / 94$ & خاى & r \\
\hline$O / T Y$ & $r / 0$ & $r q / 9$ & 0 & $r / q$ & $q 4 / 4$ & 14 & $4 / q$ & خاكدانه ريز & \\
\hline$\circ / T Q$ & $r / 0$ & $T Y / T$ & $10 / 1$ & $r / 4$ & $q \pi / 9$ & 14 & Y/AY & خاكدانه درشت & \\
\hline $0 / \pi r$ & $r / \Lambda$ & rI/9 & $I V / r$ & $r / \& V$ & $19 / 10$ & 19 & $\Delta / 1$ & خاك & r \\
\hline $0 / M Y$ & $r / v$ & 每/ & $\mid V / 1$ & $\varphi / \mu$ & $V Q / T$ & 19 & $0 / 1$ & خاكدانه ريز & \\
\hline $0 / M T$ & $\mathrm{r} / \mathrm{\Lambda}$ & $T V / \Psi$ & TYN & $r / q$ & $\Lambda r / r$ & 14 & $4 / q$ & خاكدانه درشت & \\
\hline $0 / T Q$ & $r / r$ & $r \circ / T$ & $4 / \mathrm{V}$ & r & $k y / \mu$ & 14 & Y /VG & خاى & r \\
\hline $0 / \pi r$ & $r / 9$ & $r Y / q$ & $10 / 4$ & $r / 9$ & $90 / 0$ & 10 & $Y / \Lambda \Lambda$ & خاكدانه ريز & \\
\hline$O / T Y$ & $\mu / \mu$ & $r \circ / V$ & 4 & r & $49 / 9$ & 14 & $r / v r$ & خاكدانه درشت & \\
\hline $0 / T_{1}$ & $r / \mathrm{V}$ & $r \mu / 1$ & $19 / 0$ & 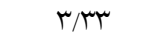 & $9 V / 0$ & ir & $r / / \Lambda T$ & خاى خ & 0 \\
\hline $0 / T_{1}$ & $r / \Lambda$ & To & $r Y / 9$ & $r / 9$ & VA/V & 14 & $Y / \Lambda \Lambda$ & خاكدانه ريز & \\
\hline $0 / \pi$ & $r / 4$ & $r \circ / 9$ & $9 / 1$ & r & $\Delta R / C$ & Ir & $\varphi / V Q$ & خاكدانه درشت & \\
\hline
\end{tabular}

$$
\text { خاكدانههاى درشت بود. }
$$

ضرايب سرعت نشان مىدهد كه آزاد شدن يتاسيم غيرتبادلى از خاكدانههاى ريز سريعتر از خاكدانههاى درشت بود. تفـاوت در ضريب سرعت آزاد شــن بتاسـيم غيرتبـادلى ممكـن اسـت بهدليل تفاوت در مقدار يتاسـيم غيرتبـادلى خاكدانسههـا، نـوع و مقدار كانى هاى رسى در بخش رس و سيلت، ريسزى و درشـتى لهـ اين كانى ها، درجه هواديدكى كانىهـا، درجـه تخليـه يتاسـيم و

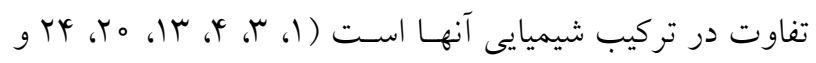
צY). ضريب سرعت آزاد شدن يتاسيم غيرتبادلى در معادله تـابع توانى كمتر از يك است؛ بنابراين با كذشـت زمـان سـرعت آزاد شدن يتاسيم كاهش مى يابد. نجفى و همكاران (1/) عوامل مؤثر

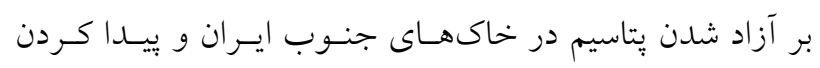
بهترين مدل براى توصيف آزاد شدن يتاسيم توسط كلريد كلسيم

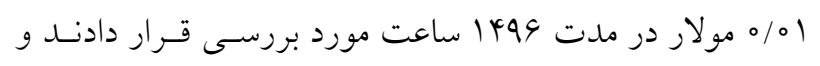
به اين نتيجه رسيدند كه بين مقدار يتاسيم تجمعسى آزاد شــده و ميزان ميكا رابطـه مسـتقيم وجـود دارد. بدرسـين و سـينگ (9)

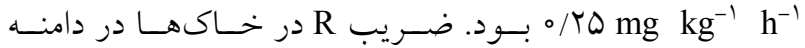
ץ تا 19 19 بود. ضريب 1/ $10^{-4}\left(\mathrm{mg} \mathrm{kg}^{-1}\right)^{-1}$

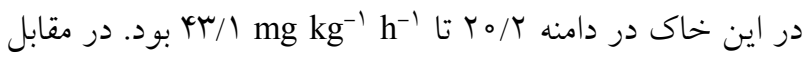

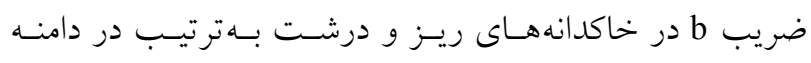
در خاكدانه درشت بود. تفاوت بين مقـادير b نشـاندهنـده تفـاوت توانايى خاكها در تـأمين پيتاسـيم اسـت. ضـريب R در معادلـه

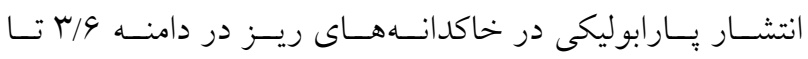

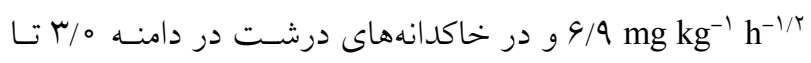

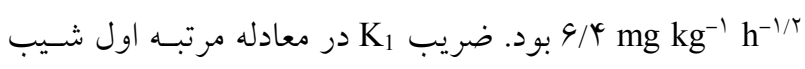
خط و نشاندهنده ضريب سرعت آزاد شدن يتاسيم اسـت و در دامنــ درشت

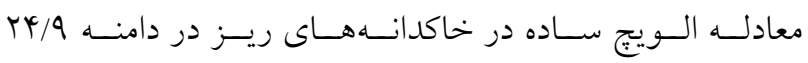
تــ F 
درباره سرعت آزاد شدن يتاسيم غيرتبادلى در 19 خـاك آهكى

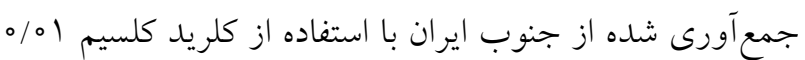

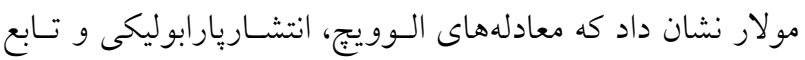
توانى به بهترين نحو رهاسازى بِتاسيم را توجيه مىنمايـــ (1).

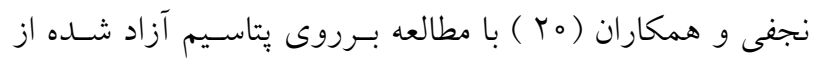

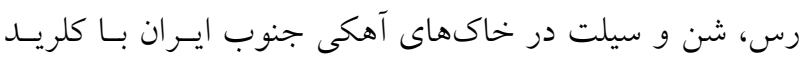

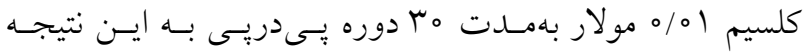

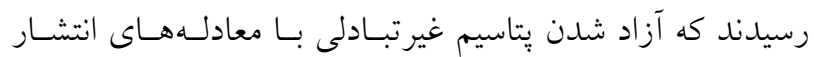
يارابوليكى و تابع توانى به بهترين نحو توصيف شد.

\section{نتيجه كيرى}

مطالعه اشكال مختلف يتاسيم در خاك و خاكدانه ريز و درشـت آن نشان داد، مقدار يتاسيم عصارهذيـرى شـــه از خاكدانـه ريـز بيشتر از مقدار آن در خاك و خاكدانه درشت بود. سـرعت آزاد شدن يتاسيم غيرتبادلى از خاكها و خاكدانهها در مراحـل اوليـه

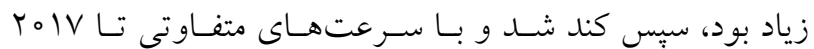
ساعت ادامه يافت. نتايج ايـن مطالعه نشــان داد مقـدار يتاسـيم

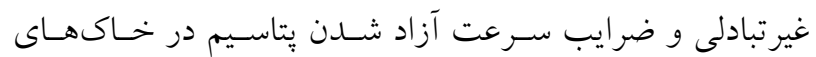
مختلف متفاوت است. بهطـوركلى مقـدار يتاسـيم تجمعسى آزاد

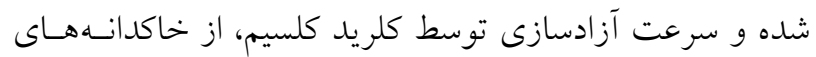

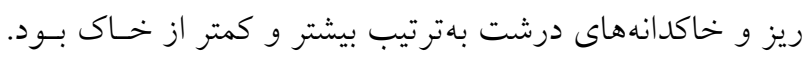

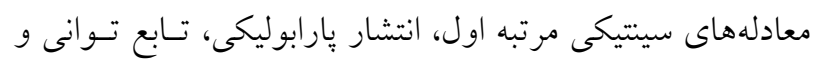

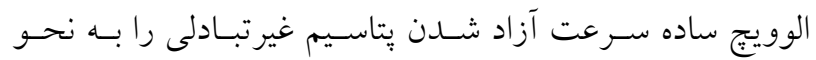
مطلوبى توصيف كردند.
سينتيك آزاد شدن يٍاسـيم را از خـاكهــاى ورتسىسـول تحــت

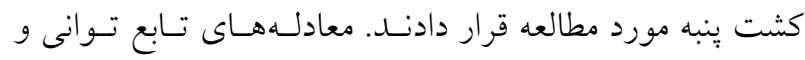

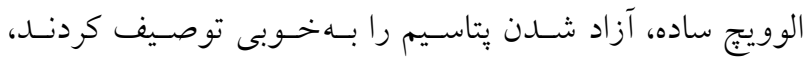

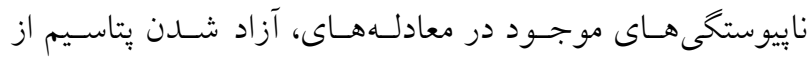
مكانهاى مختلف را تحت مكانيزمهاى كوناكون نشـان مسى داد.

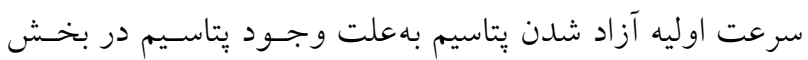

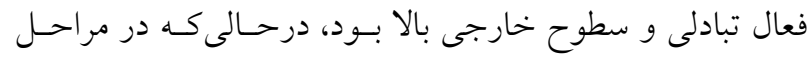

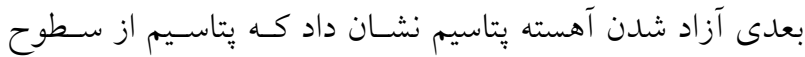
داخلى تحت كنترل فرآيند انتشار آزاد مىشود. نجفى (19) بـا لـا

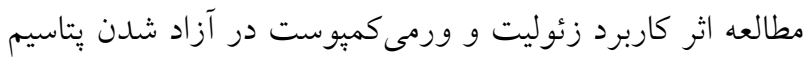
از خاكهاى آهكى دريافت كه استفاده از زئوليت بـهـــور قابـل توجهى باعث افزايش غلظت پِتاسيم محلول و تبادلى مى شـود و

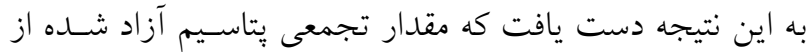

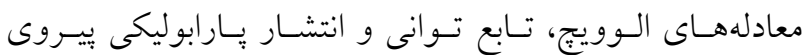

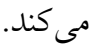
رائو (Yr) سيتيك آزاد شدن يتاسيم را در مزارع سيبزمينى

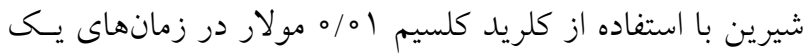

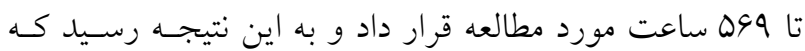
مقدار يتاسيم غيرتبادلى آزاد شده در زمانهاى مختلف با استفاده

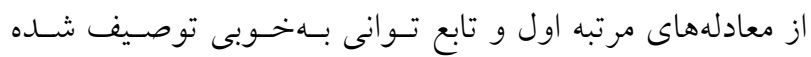

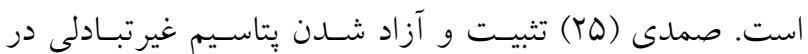
مزارع با كشت هاى مداوم در مناطق شمال غرب ايران با استسفاده

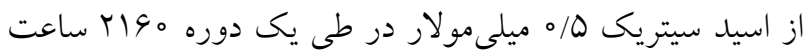

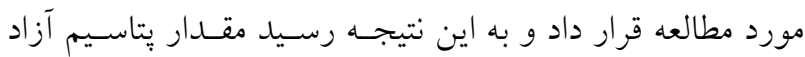

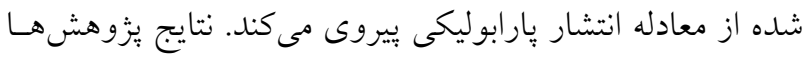

\section{منابع مورد استفاده}

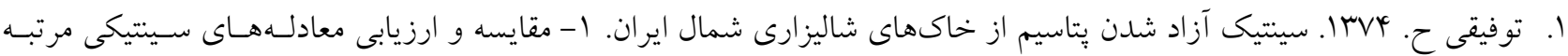

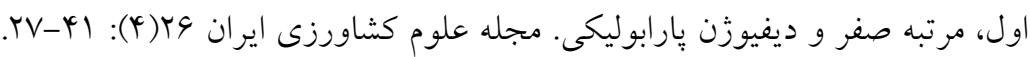

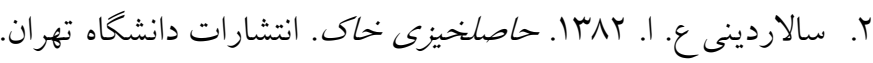
r. حسين يور ع. ر. rیrا. كاربرد مطالعات سيتتيكى در توصيف آزادسازى يتاسيم غير تبادلى در شمارى از خاكهاى همدان. علسوم و و

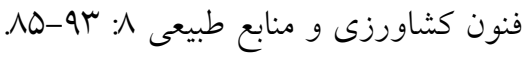




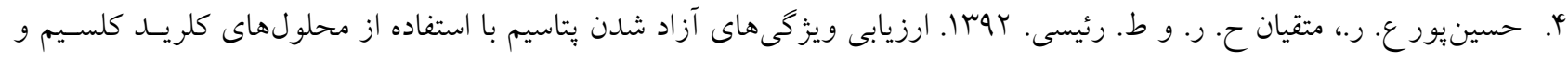

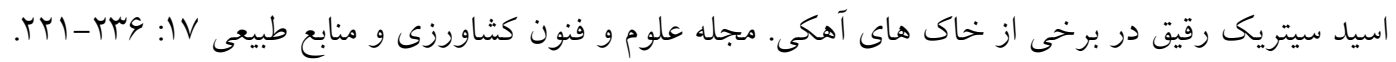

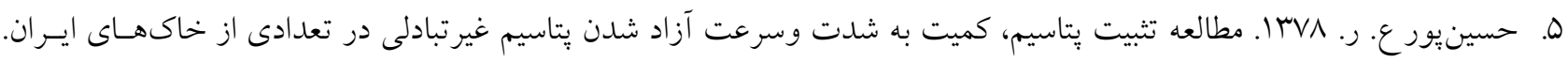

$$
\begin{aligned}
& \text { ياياننامه دكترى خاكشناسى، دانشكده كشاورزى، دانشخاه صنعتى اصفهان. ايران. } \\
& \text { 9. فرشادىراد، ا.، دردىيور، ا. و ف. خرمايى. اهبا. سرعت آزادشدن يتاسيم غيرتبادلى از خاك و اجزاى آن در تعدادى از خاكهاى } \\
& \text { استان كلستان. مجله علوم و فنون كشاورزى و منابع طبيعى 19: ه } \\
& \text { V. نوربخش، ف. و م. كريميان اقبال. وV Irا. حاصلخيزى خاك (ترجمه). انتشارات دانشخاه صنعتى اصفهان. اصفهان. }
\end{aligned}
$$

8. Al-Kanani, T., A. F. Mackenzie and G. L. Ross. 1984. Potassium status of some quebec soils: K release by nitric and sodium teteraphenylboran as related to particle size and mineralogy. Canadian J. Soil Sci. 64:99-106.

9. Bedrossian, S. and B. Sing. 2004. Kinetics of potassium rlease from Vertisols from northern NSW, Super Soil 2004: $3^{\text {rd }}$ Australian New Zealand Soils Conference, University of Sydney, Australia.

10. Bertsch, P. M. and G. W. Thomas. 1985. Potassium status of temperate region soil. PP: 131-162. In: R. E. Munson (Ed.), Potassium in Agriculture. ASA, Madison. Wisconsin.

11. Cox, A. E. and B. C. Joern. 1997. Release kinetics of nonexchangeable potassium in soil using sodium tetraphenylboron. Soil Sci. 162: 588-596.

12. Gee, G. H. and J. W. Bauder. 1986. Partical size analysis. PP: 383-411. In: A. Klute (Ed.), Methods of Soil Analysis. Part 2: Physical Properties. Soil Science Society of America, Madison, Wisconsin.

13. Hosseinpour, A. R. and M. Kalbasi. 2002. Kinetics of non-exchangeable potassium from soil and separatesin some central region soils of Iran. In: Proceeding of the $17^{\text {th }}$ Wold Congress of Soil Science. Bangkok, Thailand.

14. Jalali, M. 2005. Release kinetics of nonexchangeable potassium in calcareous soils. Commun. Soil Sci. Plant Anal. 36:1903-1917.

15. Knudsen, D. G. A. Peterson and P. F. Partt. 1982. Lithium, sodium, and potassium. PP: 225-246. In: A. L. Page, R. H., Miller and D. R. Keeney (Eds.), Methods of Soil Analysis. Part 2: Chemical and Microbiological Properties. ( $2^{\text {nd }}$ ed.). American Society of Agronomy and Soil Science Society of America, Madison, Wisconsin.

16. Mengle, K., Rahmatullah and H. Dou. 1998. Release of potassium from the silt and sand fraction of loess- derived soils. Soil Sci. 163(10): 805-813.

17. Nelson, D. W. and L. E. Summers. 1996. Total carbon organic carbon and organic matter. PP: 961-1010. In: D. L. Sparks (Ed.), Method of Soil Analysis. Soil Science Society of America. Madison. Wisconsin

18. Najafi-Ghiri, M. 2014. Effects of zeolite and vermicompost applications on potassium release from calcareous soils. Soil and Water Res. 9(1): 31-37.

19. Najafi-Ghiri, M., Abtahi, A., Karimian, N., H. R. Owliaie and F. Khormali. 2011. Kinetics of non-exchangeable potassium release as a function of clay mineralogy and soil taxonomy in calcareous soils of southern Iran. Arch. Agron. Soil Sci. 57(4): 343-363.

20. Najafi-Ghiri, M., A. Abtahi, S. Hashemi and F. Jaberian. 2012. Potassium release from sand, silt and clay fractions in calcareous soils of southern Iran. Arch. Agron. Soil Sci. 58(12):139-1454

21. Page, A. L., R. H. Miller and D. R. Jeeney. 1992. Methods of Soil Analysis, Part 1. Physical Properties. Soil Science Society of America. Madison.

22. Rao, R. B. K. 2015. Kinetics of potassium release in sweet potato cropped soils: Acase study in the highlands of papua new guinea. Solid Earth. 6(1): 217-225.

23. Rhodes, J. D. 1996. Salinity: electrical conductivity and total dissolved solids. PP: 417-435. In: D.L. Sparks (Ed.), Methods of Soil Analysis. Part 3: Chemical Properties. Soil Science Society of America, Madison, Wisconsin.

24. Srinivasarao, C., A. Subba Rao and T. R. Rupa. 2000. Plant mobilization of soil reserve potassium from fifteen senectitic soils in relation to soil test potassium and mineralogy. Soil Sci. Soc. of Am. J. 165(7): 578-586.

25. Samadi, A. 2010. Long-term cropping on potassium release and fixation behaviors. Arch. Agron. Soil Sci. 56(5): 499-512.

26. Song, S. K. and P. M. Huang. 1988. Dynamic of potassium release from potassium bearing minerals as influenced by oxalic and citric acid. Soil Sci. Soc. Am. J. 52:383-390.

27. Sparks, D. L. 1987. Potassium dynamics in soils. Soil Sci. 6: 1-63.

28. Shaggs, T. H., L. M. Arya, P. J. Shouse and B. P. Mohanty. 2001. Estimating particle size distribution from limited. Soil texture data. Soil Sci. Soc. Am. J. 65:1038-1044.

29. Thomas, G. W. 1996. Soil pH and soil acidity. PP. 1404-1414. In: D. L. Sparks (Ed.), Methods of Soil Analysis. 
Part 3: Chemical Properties. Soil Science Society of America and America Society of Agronomy, Madison, Wisconsin, PP: 475-490.

30. Vikas, S. and K. N. Sharma. 2011. Potassium release kinetics in potato growing Alluvial soils of north western India. Soil Sci. 42: 1404-1414. 


\title{
Kinetics of Non-exchangable Potassium Release in Aggregates with Different Sizes in a Number of Calcareous Soils
}

\author{
S. Z. Atar Shahraki, A. R. Hosseinpur, H. R. Motaghian* and Sh. Ghorbani ${ }^{1}$
}

(Received: Jan. 18-2016; Accepted: Jan. 24-2018)

\begin{abstract}
The study of the kinetics of non-exchangeable potassium (NEK) release is very important for a better understanding of $\mathrm{K}$ availability for plants in different soils. Moreover, aggregates with different sizes have different effects on the release of nutrients. Therefore, the aim of this study was to examine the release of NEK in 5 calcareous soils of chaharmahalva- bakhtiari province, and small and large aggregates $(<250 \mu \mathrm{m}$ and $>250 \mu \mathrm{m})$ using $\mathrm{CaCl}_{2} 0.01 \mathrm{M}$ at $25 \pm 1^{\circ} \mathrm{c}$ for 2 $2017 \mathrm{~h}$. The results showed that cumulative released NEK in soils, and small and large aggregates was 173.5-372.7, 215.1-426.1 and 178.9-381.5 mg kg-1, respectively. The results revealed that coefficients of the cumulative released NEK in small aggregates was lower than those of the soils and large aggregates. Based on the coefficient of determination $\left(\mathrm{R}^{2}\right)$ and standard error $(\mathrm{SE})$, the released NEK was well described by the first order, the power function, parabolic diffusion, and simplified Elovich equations. The rate coefficients of the release of $\mathrm{K}$ were different in different soils. The cumulative released amount of $\mathrm{K}$ and its rate of release in a solution of calcium chloride in small aggregates was more than those of large aggregates.
\end{abstract}

Keywords: Release of none exchangeable potassium, Aggregates, Calcium chloride, Kinetics equations.

1. Dept. of Soil Sci., Faculty of Agric., Shahrekord Univ., Shahrekord, Iran.

*: Corresponding Author, Email: motaghian.h@yahoo.com 